\title{
Epo-induced erythroid maturation is dependent on Plcy1 signaling
}

\author{
TM Schnöder ${ }^{1}$, P Arreba-Tutusaus ${ }^{1}$, I Griehl', L Bullinger ${ }^{2}$, M Buschbeck ${ }^{3}$, SW Lane ${ }^{4}$, K Döhner $^{2}$, C Plass ${ }^{5}$, DB Lipka ${ }^{1,5,6}$, FH Heidel ${ }^{1,6}$ \\ and T Fischer ${ }^{1,6}$
}

Erythropoiesis is a tightly regulated process. Development of red blood cells occurs through differentiation of hematopoietic stem cells (HSCs) into more committed progenitors and finally into erythrocytes. Binding of erythropoietin (Epo) to its receptor (EpoR) is required for erythropoiesis as it promotes survival and late maturation of erythroid progenitors. In vivo and in vitro studies have highlighted the requirement of EpoR signaling through Janus kinase 2 (Jak2) tyrosine kinase and Stat5a/b as a central pathway. Here, we demonstrate that phospholipase C gamma 1 (Plc $\gamma 1)$ is activated downstream of EpoR-Jak2 independently of Stat5. Plc $\gamma 1$ deficient pro-erythroblasts and erythroid progenitors exhibited strong impairment in differentiation and colony-forming potential. In vivo, suppression of PIc $\gamma 1$ in immunophenotypically defined HSCs $\left(\mathrm{Lin}^{-} \mathrm{Sca1}^{+} \mathrm{KIT}^{+} \mathrm{CD} 48^{-} \mathrm{CD} 150^{+}\right.$) severely reduced erythroid development. To identify Plc $\gamma 1$ effector molecules involved in regulation of erythroid differentiation, we assessed changes occurring at the global transcriptional and DNA methylation level after inactivation of PIc $\gamma 1$. The top common downstream effector was H2afy2, which encodes for the histone variant macroH2A2 (mH2A2). Inactivation of mH2A2 expression recapitulated the effects of Plc $\gamma 1$ depletion on erythroid maturation. Taken together, our findings identify Plc $\gamma 1$ and its downstream target mH2A2, as a 'non-canonical' Epo signaling pathway essential for erythroid differentiation.

Cell Death and Differentiation (2015) 22, 974-985; doi:10.1038/cdd.2014.186; published online 14 November 2014

Erythropoiesis is a dynamic and tightly regulated process that allows the daily production of large numbers of circulating red blood cells originating from hematopoietic stem cells (HSCs). This process involves concerted progression through different stages accompanied by temporally regulated changes in cell surface protein expression, a reduction in cell size, progressive hemoglobinization and nuclear condensation and extrusion. ${ }^{1}$ Regulation of survival, expansion and differentiation of erythroid progenitors is dependent on several transcription factors and an intricate network of complex and finely tuned regulatory signaling pathways. ${ }^{2,3}$ In vivo and in vitro studies have highlighted the importance of erythropoietin (Epo) receptor (EpoR) signaling through Janus kinase 2 (Jak2) tyrosine kinase in regulation of red blood cell production thereby preventing committed erythroid progenitors from undergoing apoptosis and facilitating proliferation and differentiation. ${ }^{1}$ In vivo knockout of either Epo or EpoR leads to a 5- to 20-fold reduction in number of circulating primitive erythroblasts during embryogenesis (day E11.5) and mice die because of severe anemia by day E13.5. ${ }^{4}$ Stat5 is critical during fetal erythropoiesis and Stat $5 a^{-1-} 5 b^{-1-}$ embryos become severely anemic by day 13.5 (E13.5). This is primarily due to increased apoptosis of Stat5a and $5 \mathrm{~b}$-deficient erythroid progenitors. ${ }^{5,6}$ Adult Stat5 $\mathrm{a}^{-/-} 5 \mathrm{~b}^{-/-}$mice partially
(30-50\%) show equal numbers of red cells, hemoglobin levels and hematocrit as wild-type controls. However, anemic adult STAT5 knockout mice revealed an increase in early erythroblast numbers, which fail to differentiate. ${ }^{7}$ Studies of EpoR signaling in vitro indicate that red cell differentiation and survival of erythroid progenitors is also driven by additional events other than Stat5 signaling, including pathways downstream of phospoinositide-3 kinase. ${ }^{8-10}$ Interestingly, genetic deletion of murine phosphatidylinositol-specific phospholipase $\mathrm{C}$ gamma $1(P / c \gamma 1)$ using a germline knockout mouse model resulted in embryonic lethality at day E9.0 because of generalized growth failure and absence of erythropoiesis and vasculogenesis. ${ }^{11}$ Plc $\gamma 1$ is known to act as key mediator of calcium signaling that can substitute for PI3K/Akt signaling in oncogenic models. ${ }^{12}$ It is a signaling mediator that acts downstream of several membrane receptors (such as T-cell receptor) and non-membrane bound kinases such as Jak2 or Bcr-Abl. Expression of Plcy2 could not substitute for the aforementioned defects in $P l c 1^{-1-}$ embryos. Deletion of one Plc 1 allele in embryonic development did not lead to any detectable difference in comparison with wild-type embryos indicating a correlation between disease phenotype and the proportion of $P l c \gamma 1$ alleles. ${ }^{13}$ Knockdown of $P / c \gamma 1$ in zebrafish embryos confirmed a role for $\mathrm{Plc} 1$ in early erythroid

\footnotetext{
${ }^{1}$ Department of Hematology and Oncology, Center for Internal Medicine, Otto-von-Guericke University Medical Center, Magdeburg, Germany; ${ }^{2}$ Internal Medicine III, Department of Hematology/Oncology, University Hospital Ulm, Ulm, Germany; ${ }^{3}$ Institute of Predictive and Personalized Medicine of Cancer (IMPPC), Campus Can Ruti, Badalona, Spain; ${ }^{4}$ Division of Immunology, QIMR Berghofer Medical Research Institute, Herston, Brisbane, Australia and ${ }^{5}$ Division of Epigenomics and Cancer Risk Factors (C010), German Cancer Research Center, Heidelberg, Germany

${ }^{*}$ Corresponding author: T Fischer, Department of Hematology and Oncology, Center for Internal Medicine, Otto-von-Guericke University Medical Center, Leipzigerstr. 44, 39120 Magdeburg, Germany. Tel: +49 39167 13266; Fax: +49 39167 13267; E-mail: Thomas.Fischer@med.ovgu.de

${ }^{6}$ These authors contributed equally to this work.

Abbreviations: CMP, common myeloid progenitor; Epo, erythropoietin; EpoR, erythropoietin receptor; FLC, fetal liver cells; GMP, granulocyte-macrophage progenitor; HSC, hematopoietic stem cell; Jak2, Janus kinase 2; MEP, megakaryocyte-erythroid progenitor; PIc $\gamma 1$, phospholipase C gamma 1

Received 09.4.14; revised 18.9.14; accepted 06.10.14; Edited by R De Maria; published online 14.11.14
} 
differentiation. ${ }^{14}$ All these results point to a major role for $\mathrm{Plc} \gamma 1$ in regulation of erythroid development. However, as outlined above, Stat5 is generally considered to be the 'canonical' major driver downstream of EpoR-Jak2-mediated erythropoiesis. Here, we investigated the role of an alternative 'noncanonical' signaling pathway (Plc $\gamma 1)$ essential for erythroid differentiation.

\section{Results}

Plcy1 is directly activated by EpoR-Jak2. Although Plcy1 has been already described to have a role in formation of early erythropoiesis in a straight gene knockout mouse model, ${ }^{11}$ the molecular signaling mechanisms involved in this observation remained elusive. To address this caveat regarding the role of $\mathrm{Plc} 1$ during erythropoiesis, we first investigated whether Plcy1 is activated downstream of Epo receptor. We used an antibody that recognizes tyrosine phosphorylation at residue 783. This tyrosine is a bonafide activation site of $\mathrm{Plc} 1$, phosphorylated by various receptor

and non-receptor tyrosine kinases. ${ }^{15,16}$ Upon Epo stimulation, phosphorylation of known downstream molecules such as Stat5, Akt and Mek could be demonstrated in lymphoid (Ba/F3) and myeloid (32D) murine progenitor cell lines (both stably transfected with EpoR and Jak2-WT) and in a murine erythroid progenitor (I/11) cell line (Figure 1a). ${ }^{17}$ Pharmacologic inhibition of EpoR signaling using a JAK inhibitor resulted in strong reduction of $\mathrm{Plc} \gamma 1$ phosphorylation (Figure 1a). To gain further evidence that $\mathrm{Plc} 1$ is directly regulated by EpoR-Jak2 signaling, we performed a kinetic experiment. The respective cells were starved and then re-stimulated with Epo for the indicated time points (Figure 1b). Phosphorylation of Plcy 1 was detectable upon 1 min of Epo stimulation, presented a peak at $5 \mathrm{~min}$ and decreased after 20 min of Epo stimulation (Figure 1b). Stat5 phosphorylation was monitored as a control and showed similar results (Figure1b; data not shown). Next, we investigated whether $\mathrm{Plc} \gamma 1$ activation is transcriptionally regulated through EpoRJak2 signaling. For this purpose, we inhibited global cellular gene-transcription by Actinomycin $D$ and re-stimulated the

b

a

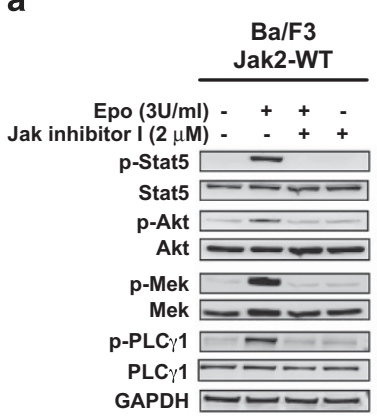

c

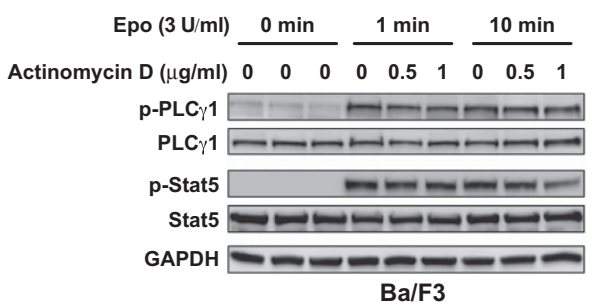

e

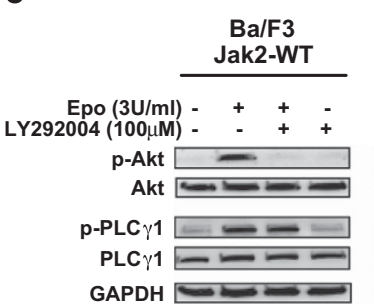

$\mathrm{Ba} / \mathrm{F} 3$
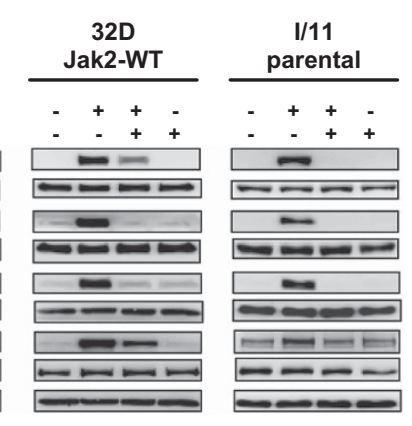

d

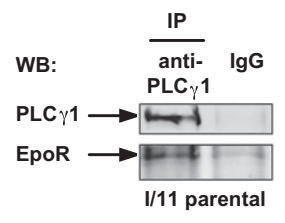

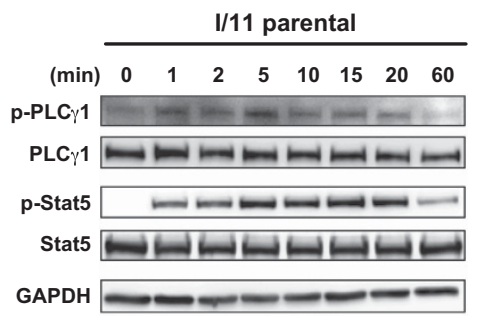

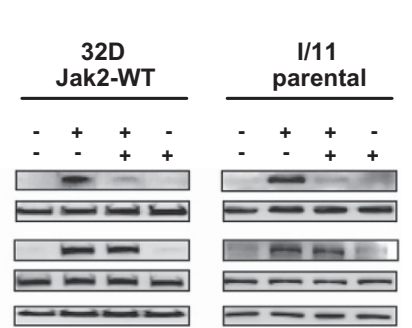

f

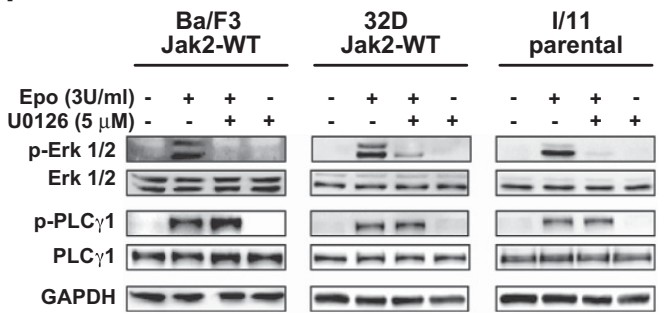

Figure $1 \mathrm{Plc} \gamma-1$ is a direct downstream target of EpoR-Jak2 signaling. (a) Western blot analysis of Ba/F3 and 32D cells stably transfected with EpoR and Jak2-WT and of the erythroid progenitor cell line 1/11. Analysis was performed using phospho $(p)$ and total antibodies. These data are representative results of three independent experiments. (b) Kinetic analysis of the erythroid progenitor cell line l/11. These blots are representative results of three independent experiments. (c) Western blot analysis of cells treated with Actinomycin $D(2 \mathrm{~h} ; 0.5,1 \mu \mathrm{g} / \mathrm{ml})$. These data are representative results of three independent experiments. (d) Co-immunoprecipitation of Plc $\gamma-1$ and EpoR in erythroid progenitor cells (I/11). Immunoprecipitation was performed with antibodies specific for Plc $\gamma$-1. Western blotting of the precipitate was performed with anti-EpoR antibodies. These data are representative results of three independent experiments. (e and f) Western blot analysis of Ba/F3 and 32D cells stably transfected with EpoR and Jak2-WT and of the erythroid progenitor cell line I/11. Cells were treated with LY292004 $(1 \mathrm{~h} ; 100 \mu \mathrm{M})$ and U0126 $(1 \mathrm{~h} ; 5 \mu \mathrm{M})$, respectively. These blots are representative results of three independent experiments 
cells with Epo. Plcy 1 activation was detectable immediately after short stimulation (1 min) with Epo and did not change by pre-incubation with Actinomycin $D$ within the time period investigated (Figure 1c). To confirm Plcy1 binding to EpoRJak2, which already has been described in other cellular models, ${ }^{18,19}$ co-immunoprecipitation experiments were performed in $1 / 11$ pro-erythroblast cells. These results indicate that Plcy1 is physically associated with EpoR (Figure 1d). PI3K signaling is known to be activated downstream of EpoR and has a central role in controlling cell survival and cell cycle progression. ${ }^{20,21}$ To investigate whether $\mathrm{Plc} \gamma 1$ is dependent on PI3K/Akt signaling downstream of EpoR, we treated the Jak2-WT expressing cell lines (Ba/F3, 32D and $\mathrm{I} / 11$ ) investigated with the PI3K inhibitor LY292004. However, PI3K inhibition did not affect Plcy1 phosphorylation (Figure 1e). Binding of Epo to its receptor activates the catalytic activity of several mitogen-activated protein kinases, including extracellular-regulated kinases $1 / 2$, which participates in mitogenesis. ${ }^{22}$ To determine whether activation of Plcy 1 is affected by MAPK pathway, we treated different cell lines with the Mek inhibitor U0126. Similarly, inhibition of Mek did not result in aberrant $\mathrm{Plc} 1$ phosphorylation (Figure 1f).

\section{Plcy1 is required for erythroid differentiation and colony} formation of pro-erythroblasts. Next, we sought to determine if Plcy1 has a functional role downstream of the EpoR-Jak2 axis. Therefore, we used the murine pro-erythroblast cell line $\mathrm{l} / 11$ that is able to differentiate into mature reticulocytes/erythrocytes upon dexamethasone-/ stem cell factor-withdrawal combined with Epo stimulation (Figure 2a). 1/11 cells are erythroid progenitor cells at the stage of pro-erythroblasts derived from mouse fetal liver cells (FLCs; E13.5). They are considered to faithfully execute essential steps of erythropoiesis. ${ }^{17}$ To examine different erythroid differentiation stages, we used a flow cytometry assay that allows quantitative assessment of the maturation stage of differentiating erythroblasts. ${ }^{23}$ Interestingly, knockdown of Plc 1 1 (Figure 2b; Supplementary Figure S1a) led to a delay in erythroid differentiation and accumulation of immature erythroid progenitors (pro-erythroblasts, TER $119^{+}$CD $44^{\text {high }}$ ) (Figure 2c). Upon culture for 4 days on differentiation medium, Plc $\gamma 1$-deficient cells showed morphological characteristics of early erythroblasts, whereas the control cells morphologically resembled reticulocytes (Figure 2d). To ascertain whether the effect of Plcy1 knockdown on erythroid differentiation is direct or indirect, we examined the survival, proliferation and cell cycle distribution of Plcy1-deficient cells in comparison with control cells. Knockdown of Plc 1 altered neither survival (Figure 2e), proliferation nor cell cycle distribution of the cells (Supplementary Figures S1b and c). Of note, activation of other EpoR downstream molecules such as Stat5, Mek and Akt was not impaired by Plc 1 knockdown (Figure 2f). In order to investigate the impact of $\mathrm{Plc} 1$ suppression on colony-forming potential of erythropoietic cells, we infected I/11 parental cells with either two different Plc 1 shRNAs or control shRNA (scrambled, scr) and seeded the cells in methylcellulose supplemented with cytokines. As shown in Figure $3 a$, erythroid colony formation was significantly impaired in cells after Plcy1 knockdown compared with scrambled control. Furthermore, flow cytometric analysis of erythroid colonies revealed a higher amount of immature erythroid cells (TER119 ${ }^{+} \mathrm{CD} 44^{\text {high }}, \mathrm{c}-\mathrm{Kit}^{+}$) in Plcy1-deficient cells as compared with control cells. The content of TER119positive cells reflecting more mature cells as reticulocytes/ erythrocytes was strongly reduced in Plc 1 1-deficient cells (Figure 3b). To confirm these results, we next infected primary FLCs, harvested at day $\mathrm{E} 13.5$, with either $\mathrm{Plc} \gamma 1$ shRNAs or control shRNA (Figure $3 c$ ) and seeded the cells in methycellulose. As shown in Figure 3d, knockdown of Plcy1 led to a significant reduction of erythroid colony formation in Plcy1-deficient FLCs in vitro. When analyzing the colonies by flow cytometry, reduction of mature erythroid cells (TER119 ${ }^{+}$) and increased numbers of immature erythroid cells (TER $119^{+}$CD44 ${ }^{\text {high }}, \mathrm{c}^{-\mathrm{Kit}^{+}}$) were detectable (Figure 3e). These findings provided evidence that $\mathrm{Plc} \gamma 1$ regulates terminal erythroid differentiation in FLCs.

In vitro and in vivo erythroid differentiation of adult bone marrow (BM) cells is dependent on PIcy1. Fetal liver erythropoiesis replaces primitive erythropoiesis of the yolk sac and Epo-EpoR signaling was shown to be essential for the production of definitive erythroid lineages. ${ }^{24,25}$ As fetal liver hematopoiesis reflects an early stage of hematopoietic development, this indicates that $\mathrm{Plc} \gamma 1$ also regulates maturation and differentiation of early erythroid cells. As fetal liver hematopoiesis is biologically different to steady-state adult hematopoiesis, ${ }^{26,27}$ we aimed to recapitulate these experiments in adult BM. Using sorted BM cells from adult mice, we investigated whether earlier stages of the hematopoietic hierarchy may also be regulated through Plc $\gamma 1$ in myeloid/ erythroid differentiation. First, we analyzed the expression of Plcy1 on transcript and protein level in different compartments of the erythroid lineage. Interestingly, very high expression levels of Plcy1 could be detected in megakaryocyte-erythroid progenitors (MEPs) (Figures $4 \mathrm{a}$ and b). In addition, in pro-erythroblasts, Plcy1 levels were clearly higher as compared with erythrocytes (Figures $4 a$ and b). These results suggest an early role of $\mathrm{Plc} \gamma 1$ in triggering the development and maturation of erythroid progenitors and pro-erythroblasts rather than being essential for later stages (reticulocytes/erythrocytes) of erythroid differentiation. As $\mathrm{Plc} \gamma 1$ is the predominant isoform activated in human and mouse $\mathrm{T}$ cells downstream of the T-cell antigen receptor (TCR, CD3), ${ }^{28,29} \mathrm{Plc}$ 1 expression in CD3 T cells served as a positive control (Figures $4 a$ and b). To focus on early erythroid maturation, we generated lineage-depleted/ erythroid-enriched $\left(\mathrm{Gr}^{-}, \mathrm{B220}{ }^{-}, \mathrm{CD}^{-} / 4^{-} / 8^{-}, \mathrm{CD} 19^{-}\right.$, IL-7R $a^{-}$, TER119 ${ }^{+}$) BM cells. These cells contain HSCs, but mainly multipotent progenitors, common myeloid progenitor (CMP) cells, granulocyte-macrophage progenitor (GMP) cells, MEP cells and erythroid cells. We infected these cells with either Plcy1 or control shRNAs. Consistent with our previous findings, we could observe a significant reduction of MEP in Plcy1 knockdown cells (compared with control), whereas development of other lineages (CMP, GMP) remained largely unaffected (Figure 4c; Supplementary Figure S2a). Plating of lineage-depleted BM cells in methycellulose (as described above) revealed comparable 
a

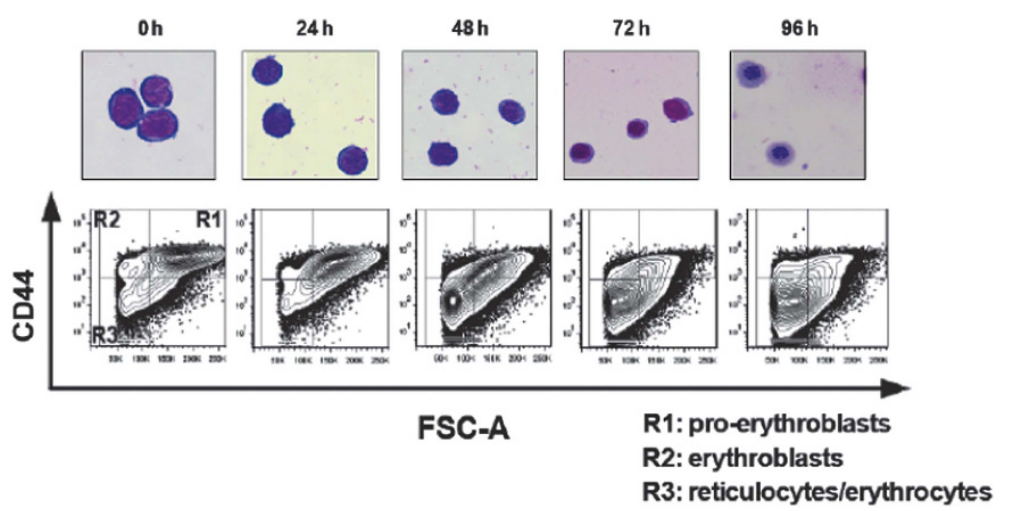

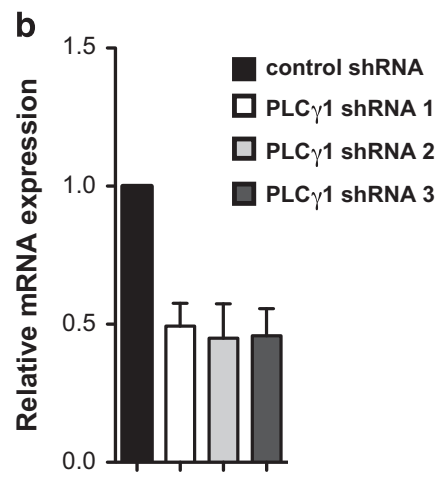

C

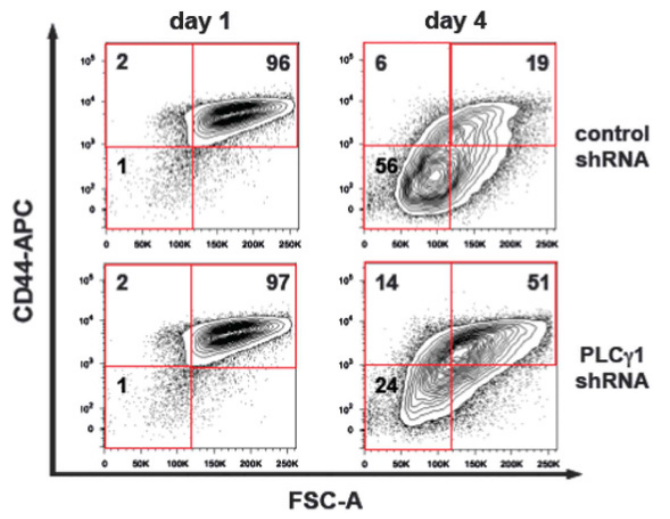

d

day 1
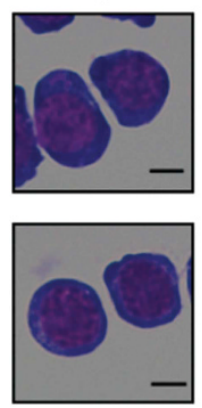

day 4
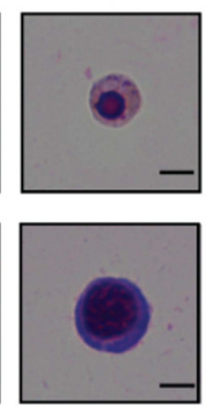

e

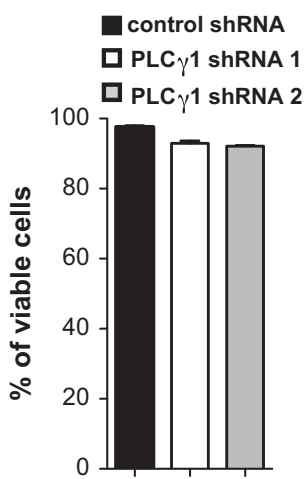

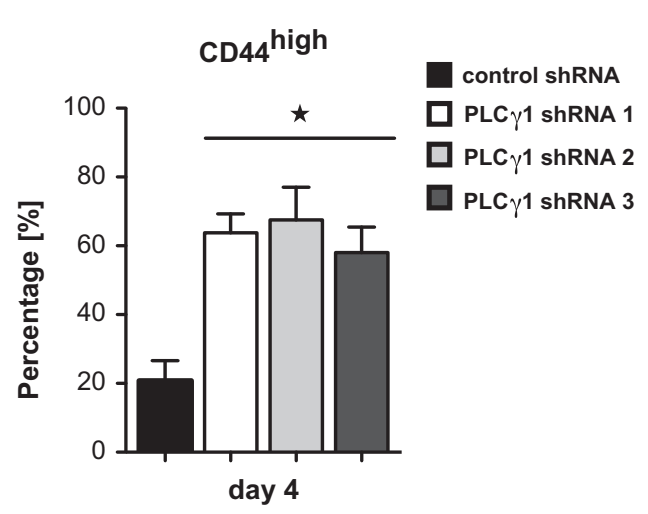

f

Figure 2 Plc $\gamma$-1 regulates differentiation of erythroid progenitors. (a) Cytospin analysis followed by Giemsa staining of cells induced to differentiate in response to Epo; for flow cytometry analysis $\mathrm{l} / 11$ cells were labeled with antibodies against TER 119 and CD44. Shown is a representative analysis of CD44 expression as function of forward scatter for all TER119-positive cells. (b) Quantitative RT-PCR of Plc $\gamma 1$ mRNA in l/11 cells after infection with either PIc 1 shRNA or control shRNA. Each experiment was done in triplicate and the error bars represent mean \pm S.D. $(n=3)$. (c) Differentiation of $1 / 11$ cells stably infected with either Plc $\gamma 1$ shRNAs or control shRNA was measured for $96 \mathrm{~h}$ (day 4 ) in response to Epo. Flow cytometry analysis was performed using antibodies against TER119 and CD44 and gating was performed as described in a; SYTOX Blue Dead Cell Stain was used to exclude dead cells. A representative FACS blot (left panel) and percentage of immature (TER $119^{+} \mathrm{CD} 44^{\text {high }}$ ) cells after $96 \mathrm{~h}$ (day 4 ; right panel) is shown. The error bars represent mean \pm S.D. $(n=3)$. (d) Representative cytospin analysis followed by Giemsa staining of Plc $\gamma 1$-deficient and control cells induced to differentiate in response to Epo. The scale bar represents $5 \mu \mathrm{m}$. (e) Survival of I/11 cells stably infected with either PIc $\gamma 1$ shRNA or control shRNA using Annexin V/SYTOX Blue staining. The error bars represent mean \pm S.D. $(n=3)$. (f) Ba/F3 cells stably expressing EpoR and Jak2-WT were transfected with control (neg.) or Plc $\gamma 1$ siRNA and were serum starved $24 \mathrm{~h}$ after knockdown and then stimulated with $3 \mathrm{U} / \mathrm{ml}$ Epo for $10 \mathrm{~min}$. Western analysis was performed using using phospho $(p)$ and total antibodies. These blots are representative results of three independent experiments

results to FLCs (Supplementary Figure S3a). Taken together, these data indicate that Plcy1 acts as a regulator during early erythroid maturation, in the initial process of cell fate determination and in maturation of erythroid progenitors. Next, we investigated the relevance of $\mathrm{Plc} 1$ on early lineage fate decision in vivo. For this purpose, we sorted immature hematopoietic cells $\left(\mathrm{Lin}^{-} \mathrm{Sca} 1^{+} \mathrm{KIT}^{+} \mathrm{CD} 48^{-} \mathrm{CD} 150^{+}\right)$derived from Ly45.1/2 donor mice and infected these cells with either GFP-labeled control shRNA or two different GFP-labeld shRNAs against Plcy1. The cells were injected in a 
a

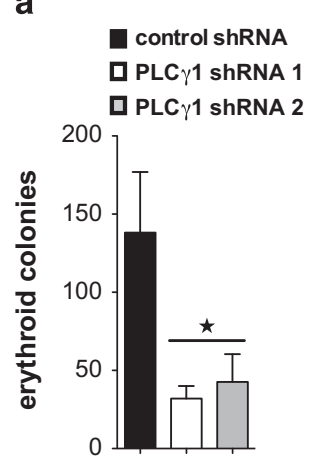

b

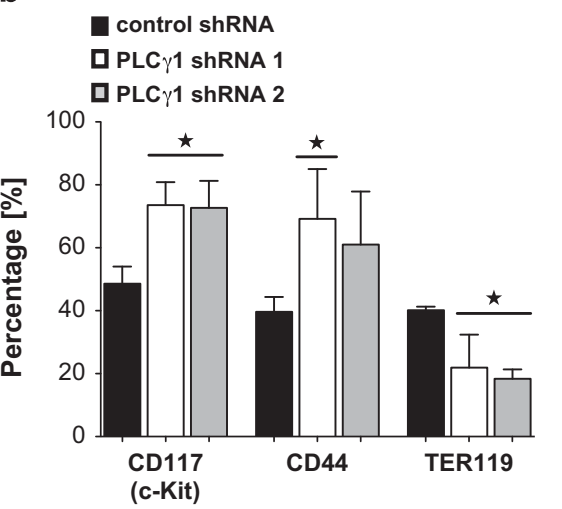

C
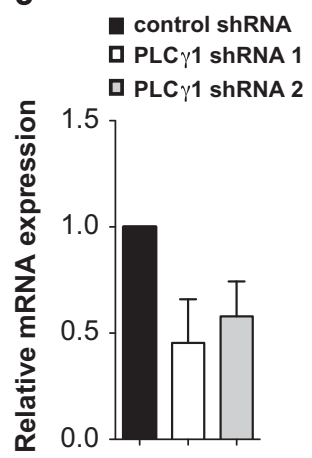

d

control shRNA 口 PLC $\gamma 1$ shRNA 1 口 PLC $\gamma 1$ shRNA 2

e

$$
\begin{aligned}
& \text { a control shRNA } \\
& \text { 口 PLC } \gamma 1 \text { shRNA } 1 \\
& \text { ם PLC } \gamma 1 \text { shRNA } 2
\end{aligned}
$$

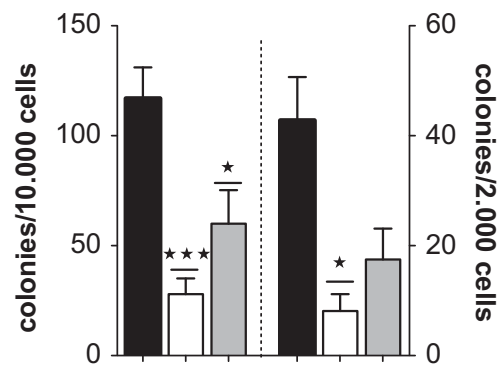

Figure $3 \mathrm{Plc} \gamma-1$ regulates colony formation in erythroid progenitors and primary FLCs. (a) $\mathrm{l} /-11$ cells infected with either Plc $\gamma 1$ or control shRNA were plated in methylcellulose supplemented with Epo $(10 \mathrm{U} / \mathrm{ml})$ and transferrin $(0.5 \mathrm{mg} / \mathrm{ml})$; colonies were counted after 10 days. Each experiment was done in triplicate, error bars represent mean \pm S.E.M. $(n=4)$. (b) Immunophenotype of colonies was investigated by flow cytometry using markers against CD44, TER119 and CD117 (c-Kit). Error bars represent mean \pm S.D. $(n=4)$. (c) Quantitative RT-PCR of PIc $\gamma 1$ mRNA in FLC after infection with either PIc $\gamma 1$ shRNAs or control shRNA. Each experiment was done in triplicate and the error bars represent mean \pm S.D. $(n=2)$. (d) FLC of C57BL/6J mice (five independent experiments, $n=5)$ were harvested at day E13.5 and infected with either Plc 1 or control shRNA. For each experiment, cells were seeded in methylcellulose supplemented with cytokines at two different concentrations ( $10000 / 2000$ cells) and colonies were counted after 10 days. Each concentration in each independent experiment was done in triplicate, error bars represent mean \pm S.E.M. (e) Immunophenotype of colonies was investigated by flow cytometry. Error bars represent mean \pm S.E.M. $(n=5)$

competitive manner along with Ly45.2 whole BM cells into lethally irradiated Ly45.2 recipient mice (Figure 4d, left panel). Twenty weeks after transplantation, BM of the respective mice was evaluated for erythroid-lineage repopulation. BM immunophenotyping for the erythroid compartment (as determined by TER $119^{+}$staining) revealed a significant decrease in erythroid lineage formation (GFP ${ }^{+}$TER $119^{+}$cells) in Plcy1-deficient recipients compared with control animals (Figure 4d). Moreover, suppression of Plcy1 led to an increased number of immature cells (GFP $\left.{ }^{+} C D 44^{\text {high }}\right)$ as compared with control animals (Figure 4d, right panel). These results suggest that inhibition of $\mathrm{Plc} \gamma 1$ signaling in early adult hematopoiesis induces a block in cell fate decision toward erythroid differentiation in vivo.

Global gene expression and methylome analysis identifies H2afy2 as a downstream target of Plcy1 during erythroid differentiation. To elucidate the mechanism of Plcy1-mediated erythroid maturation, we performed global gene expression analysis in $1 / 11$ pro-erythroblasts at defined early time points $(0,6,12$ and $22 \mathrm{~h})$ during differentiation after knockdown of $P l c \gamma 1$. Genes differentially expressed in the absence of Plcy1 could be mainly classified as transcription/co-transcription factors, epigenetic and metabolic regulators or adaptor molecules involved in intracellular signaling. The top differentially expressed genes are displayed in Figure 5a. In total, 364 probe sets (corresponding to 280 unique annotated genes) were found to be differentially regulated in Plcy1-deficient cells at all three time points (6, 12 and $22 \mathrm{~h}$ ) compared with controls (Figure 5c; Supplementary Figure S4a; Supplementary Table S2).

Stimulated by our observation that profound changes in global gene expression also included the epigenetic machinery, we speculated whether Plcy 1 signaling also modifies the global epigenetic landscape of $\mathrm{I} / 11$ pro-erythroblasts. Therefore, we performed a genome-wide DNA methylation analysis in I/11 cells upon Plc 1 knockdown using MCIP-seq (methyl$\mathrm{CpG}$ immunoprecipitation combined with next-generation sequencing). To ensure that there are no significant morphological and immunophenotypical indicators of differentiation in both the control cells and the Plcy1-deficient cells, we chose very early time points after induction of differentiation for 
a

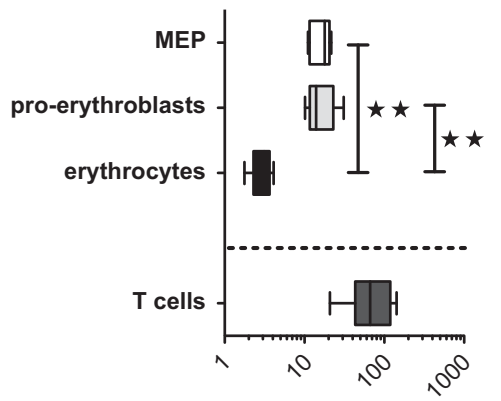

relative mRNA expression PLC $\gamma 1 /$ GAPDH b

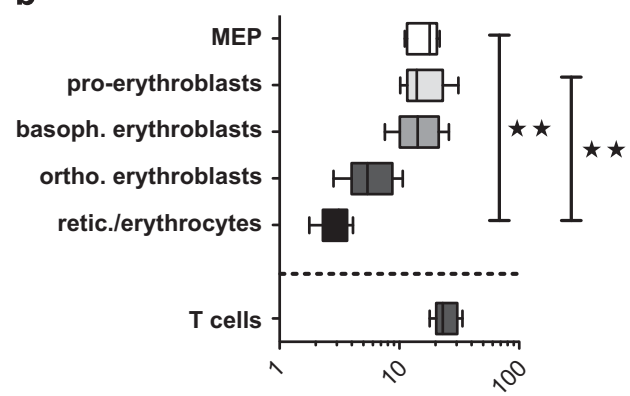

PLC $\gamma 1$ protein expression

c
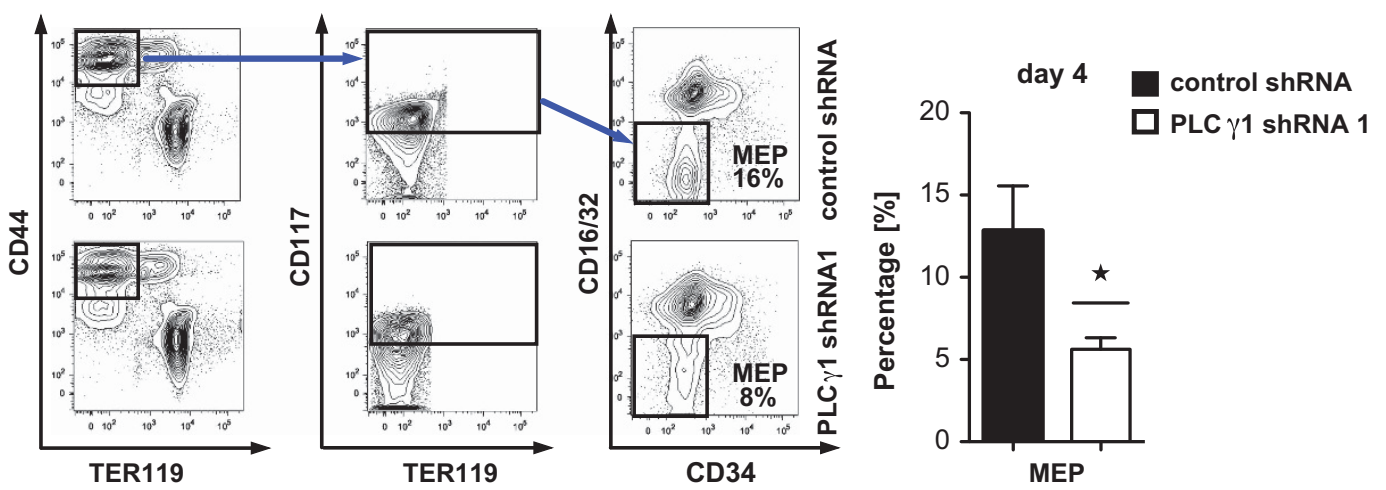

d

CD45.1/2

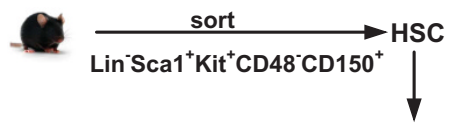

lentiviral infection with control shRNA or PLC $\gamma 1$ shRNA

(pLKO-GFP)

\begin{tabular}{l|l}
$500 \mathrm{GFP}^{+} \mathrm{HSC}$ & 250.000 supporter \\
$(\mathrm{CD} 45.1 / 2)$ & cells $(\mathrm{CD} 45.2)$
\end{tabular}

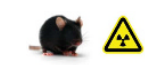

CD45.2

recipients
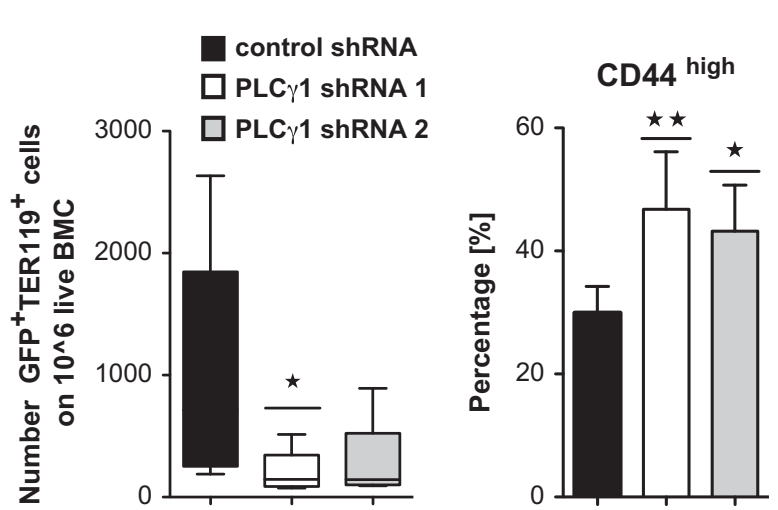

Figure $4 \mathrm{Plc} 1$ is essential for erythroid differentiation of adult BM cells in vitro and in vivo. (a) Relative expression of Plc 1 mRNA in sorted BM cells of C57BL/6J mice $(n=5)$, determined by qPCR. Each experiment was done in triplicate, error bars represent mean \pm S.D. (b) Intracellular Plc $\gamma 1$ protein expression was analyzed in different BM compartments of C57BL/6J mice $(n=5)$ using flow cytometry. Error bars represent mean \pm S.D. (c) Lineage-depleted/erythroid-enriched (Gr1-, B220-, CD3/4/8-, CD19-/IL-7R $\alpha-$ negative) BM cells of C57BL/6J mice $(n=4)$ were infected with either Plc $\gamma 1$ or control shRNA. Differentiation was measured by flow cytometry over a time period of $96 \mathrm{~h}$ (day 4 ). A representative FACS blot (left panel) and percentage of MEP cells after $96 \mathrm{~h}$ (day 4; right panel) is shown. Error bars represent mean \pm S.D. (d) Immunophenotypically defined HSC (Lin ${ }^{-}$Sca $1^{+} \mathrm{KIT}^{+} \mathrm{CD} 48^{-} \mathrm{CD} 150^{+}$) were sorted and infected with PIc $\gamma 1$ shRNA or control shRNA. $500 \mathrm{GFP}^{+}$HSCs were injected along with $2.5 \times 10^{5}$ supporter cells (whole BM) into lethally irradiated recipient mice. Twenty weeks after transplant, the mice were killed and BM was evaluated for erythroid lineage development; for flow cytometry analysis cells were labeled with antibodies against TER119 and CD44. For each group, five mice were analyzed; error bars represent mean \pm S.D. $(n=5)$

methylome analysis ( 0 and $24 \mathrm{~h})$. At each time point, we performed knockdown of Plcy1 using two different shRNA constructs. Only those autosomal regions indicative of differential methylation in both experiments were deemed to be relevant and therefore selected for further analysis. In total, at time point zero $(0 \mathrm{~h})$ we identified 1195 differentially methylated regions (DMRs). Of those, 265 (22.2\%) mapped to CpG-islands (CGI), 103 (8.6\%) mapped to CGI-shores and
$41(3.4 \%)$ were located in non-CGI promoters (Supplementary Figure S3b). At time point one $(24 \mathrm{~h})$, we identified a total of 742 DMRs, of which 306 (41.2\%), $72(9.7 \%)$ and $21(2.8 \%)$ mapped to CGls, CGl-shores and non-CGI promoters, respectively (Supplementary Figure S4b). The observed methylation changes were by far dominated by an apparent hypomethylation (952/1195 and 687/742 DMRs at 0 and $24 \mathrm{~h}$, respectively) in $\mathrm{Plc} \gamma 1$ knockdown cells as compared with 
a

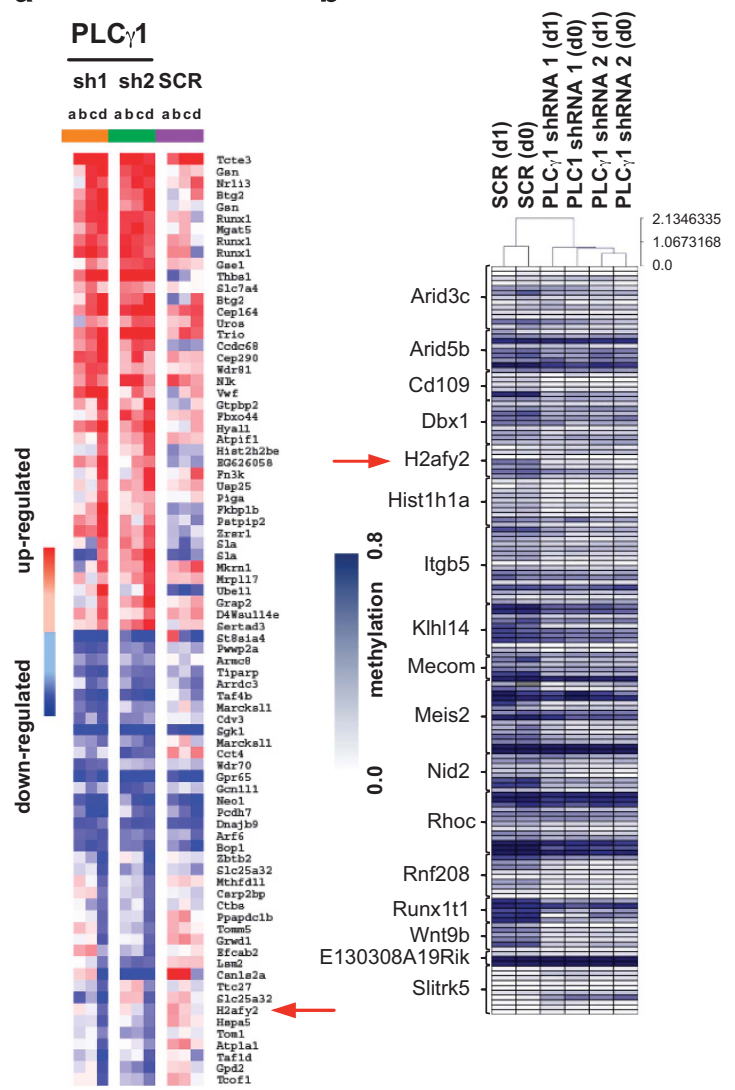

C

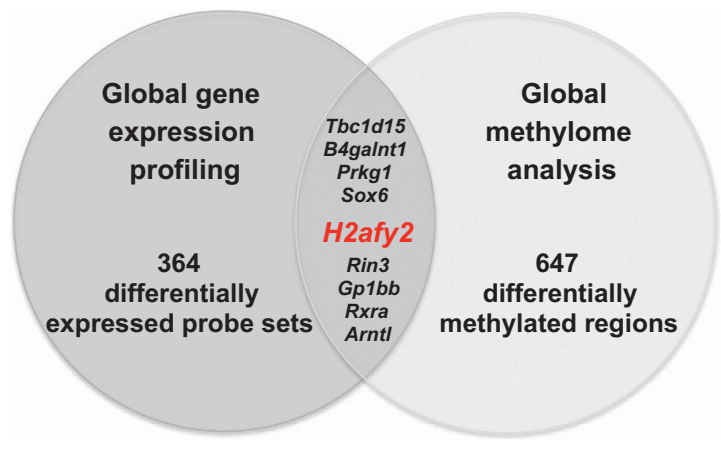

d

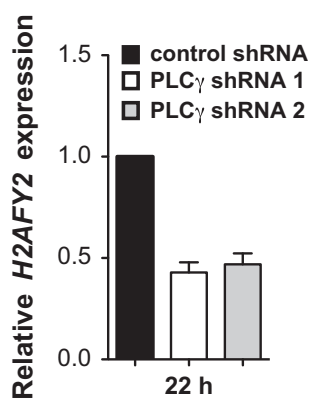

e

Figure $5 \mathrm{Plc} 1$ knockdown influences gene expression and modulates DNA methylation in I/11 erythroid progenitors. (a) Heatmap representation of the expression of most significantly upregulated (red) and downregulated (blue) genes in Plc $\gamma 1$-deficient l/11 cells (Plc $\gamma 1$ shRNA1, shRNA2) compared with control cells (scr). Fluorescence ratios were normalized by applying the Robust Multiarray Averaging analyses, we only included probe sets $(n=10078)$ whose expression varied as previously determined ${ }^{51}$ (genes with a log intensity variation of $P>0.01$ were excluded). (a) $0 \mathrm{~h}$, (b) $6 \mathrm{~h}$, (c) $12 \mathrm{~h}$, (d) $22 \mathrm{~h}$. H2afy2 is labeled with a red arrow. (b) Heatmap representation of the technical validation of 17 selected DMRs identified in our DNA methylation screening. The selection was done for log2FC of methylation enrichment and for potential biological interest of the genes. DNA methylation was measured using the MassArray technology. Each row represents a single CpG-unit. H2afy2 is highlighted with a red arrow. (c) The overlap of differentially expressed genes with DMRs revealed nine common targets. H2afy2 (highlighted in red) was the single common target among the top significantly upregulated and downregulated genes depicted in Figure 5a that showed a DMR. (d) Quantitative real-time PCR of H2afy2 expression in Plc $\gamma 1$-deficient l/11 cells $22 \mathrm{~h}$ after differentiation. Each experiment $(n=3)$ was done in triplicate and the error bars represent mean \pm S.E.M. (e) Quantitative analysis (paired $t$-test, two-tailed) of methylation changes as measured by MassArray for H2afy2

control cells. For all further analyses, we filtered for those DMRs that overlapped with either CGIs, CGI-shores, or nonCGI promoters at any time point (Supplementary Table S3; $n=647$ ), as we reasoned that these regions are more directly associated with changes in gene expression. Gene ontology analysis of DMRs revealed a highly significant enrichment of biological terms associated with regulation of cell migration, transcription and developmental processes (Supplementary Figure S4c; Supplementary Table S4).

Based on biological interest and magnitude of log2-fold change in read counts, 17 genes predicted to be differentially methylated upon Plcy1 knockdown in the MCIP-seq screening were selected for validation using the MassArray technology, a method that enables quantitative measurement of DNA methylation at single $\mathrm{CpG}$ resolution. The heatmap in Figure $5 \mathrm{~b}$ depicts methylation values of all informative CpGunits within each amplicon (for amplicon information, please refer to Supplementary Table 3). Using this approach, we were able to validate $16 / 17$ DMRs. Next, we overlapped the 647 DMRs identified in our methylome screening with the 280 significantly differentially expressed genes (based on the 364 differentially expressed probe sets). We found that nine genes showed both differential expression and differential methylation (Tbc1d1, H2afy2, B4galnt1, Prkg1, Sox6, Rin3, Gp1bb, Rxra and Arntl; Figure 5c), and H2afy2 was the only gene also present in the list of highly differentially expressed genes (Figure 5a). Knockdown of Plcy1 reduced the expression of H2afy2 and counterintuitively also the DNA methylation of the locus/promoter. H2afy2 encodes the histone variant macroH2A2 (mH2A2), which is an unusual histone with an unique domain composition found on differentiation and developmentally regulated genes. (reviewed in Buschbeck and $\mathrm{Di}\left(\mathrm{Croce}^{30}\right)$. As shown in Figure $5 \mathrm{~d}$, we could validate the downregulation of $\mathrm{H} 2 \mathrm{afy} 2$ expression upon Plc 1 knockdown by quantitative PCR (qPCR). The extent of H2afy2 methylation changes in Plc $\gamma 1$-deficient cells is quantitatively shown in Figure 5e.

Macrohistone $\mathrm{mH} 2 \mathrm{~A} 2$ is a downstream target of Plcy1 regulating erythroid differentiation. Both, $\mathrm{mH} 2 \mathrm{~A} 2$ and the 
a

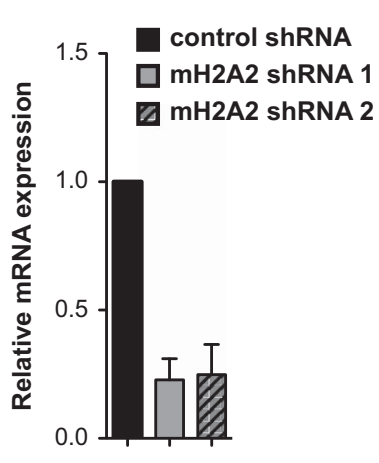

C

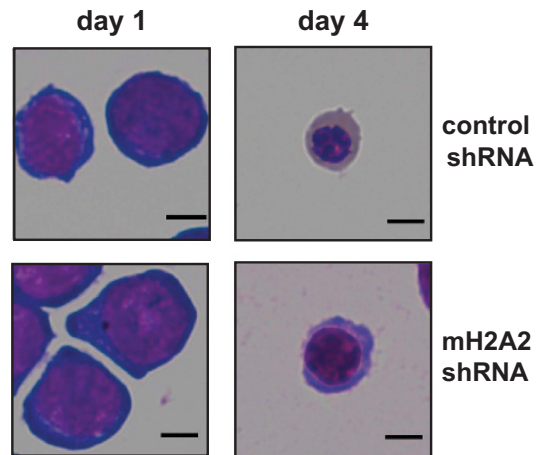

b

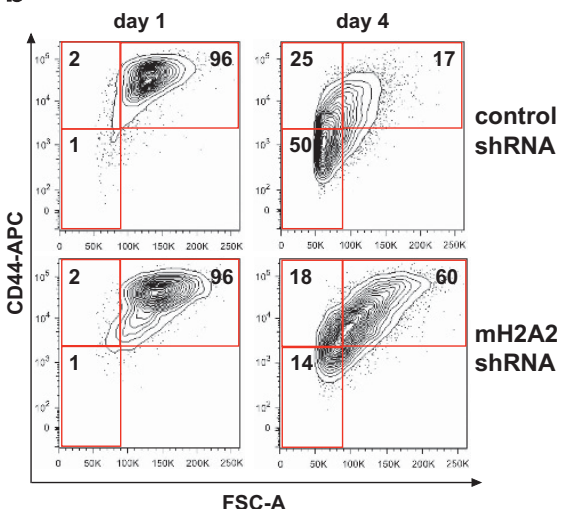

d
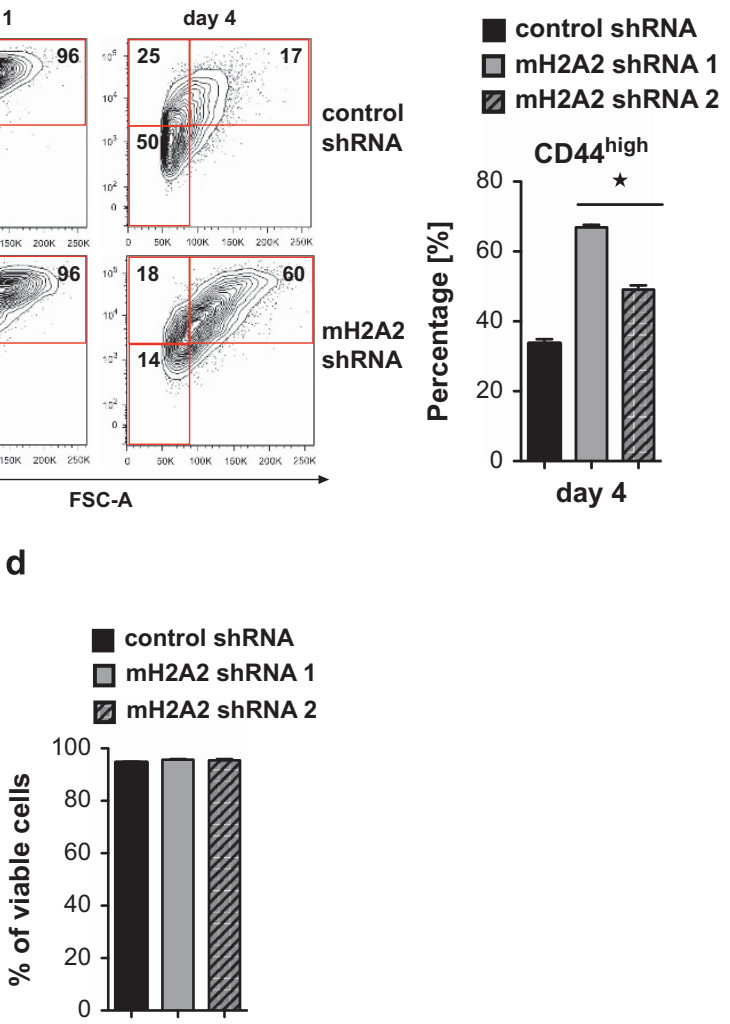

Figure 6 Macrohistone $\mathrm{mH} 2 \mathrm{~A} 2$ is regulated by Plc $\gamma 1$ and is involved in erythroid differentiation. (a) Quantitative RT-PCR of H2afy2 mRNA in l/11 cells after infection with either $\mathrm{mH} 2 \mathrm{~A} 2$ shRNA or control shRNA. Each experiment $(n=3)$ was done in triplicate and the error bars represent mean \pm S.D. (b) Differentiation of $\mathrm{l} / 11$ cells stably infected with either $\mathrm{mH} 2 \mathrm{~A} 2$ shRNAs or control shRNA was measured for $96 \mathrm{~h}$ (day 4 ) in response to Epo. A representative FACS blot (left panel) and percentage of immature $\left(\right.$ TER119+ $C D 44^{\text {high }}$ ) cells after $96 \mathrm{~h}$ (day 4; right panel) is shown. The error bars represent mean \pm S.D. $(n=4)$. (c) Representative cytospin analysis followed by Giemsa staining of $\mathrm{mH} 2 \mathrm{~A} 2$-deficient and control cells induced to differentiate in response to Epo. The scale bar represents $5 \mu \mathrm{m}$. (d) Survival of l/11 cells stably infected with either mH2A2 shRNA or control shRNA using Annexin V/SYTOX Blue staining. The error bars represent mean \pm S.D. $(n=3)$

related gene product macroH2A1, are induced during various differentiation processes $^{31,32}$ and have been shown to contribute to the establishment and maintenance of the differentiated state. ${ }^{33-35}$ Thus, we decided to investigate whether $\mathrm{mH} 2 \mathrm{~A} 2$ has a functional role in erythroid differentiation. Therefore, we infected the pro-erythroblast cell line $\mathrm{I} / 11$ with control shRNA or one of two different mH2A2 shRNAs (Figure 6a) and then analyzed for differentiation by flow cytometry. Knockdown of $\mathrm{mH} 2 \mathrm{~A} 2$ led to a strong delay in erythroid differentiation and an increase in immature cells (TER119 ${ }^{+}$CD44 ${ }^{\text {high }}$ ) as compared with control cells (Figure 6b). Morphologically, $\mathrm{mH} 2 \mathrm{~A} 2$-deficient cells showed characteristics of early erythroblasts on day 4 of differentiation, whereas cytospins of control cells revealed more differentiated cells like reticulocytes (Figure 6c). Immunophenotypically and morphologically, these results strongly resemble our findings in Plcy1-deficient pro-erythroblasts (I/11). To determine whether the effect of $\mathrm{mH} 2 \mathrm{~A} 2$ on erythroid differentiation is direct or indirect, we additionally analyzed its effect on survival, proliferation and cell cycle distribution. However, knockdown of macroH2A did not influence survival, proliferation or cell cycle in $\mathrm{I} / 11$ cells (Figure 6d; Supplementary Figures S5a and b). These data show that macrohistone variant $\mathrm{mH} 2 \mathrm{~A} 2$ is a downstream target of $\mathrm{Plc} 1$ that specifically regulates erythroid differentiation and maturation. The phenotype obtained upon $\mathrm{mH} 2 \mathrm{~A} 2$ inactivation reflected the phenotype of the Plc $\gamma 1$ knockdown in I/11 pro-erythroblasts.

\section{Discussion}

Plcy 1 has been extensively investigated in the context of signaling initiated by both receptor and non-receptor tyrosine kinases, for example, PDGF-R, EGF-R, FGF-R and VEGF$R^{36}$ Investigation of growth hormone-mediated signaling revealed that Plcy1 physically linked Jak2 and PTP-1B by binding to both using different domains. ${ }^{37}$ Immunoprecipitation studies presented here show that anti-PIc $\gamma 1$ antibody immunoprecipitated Plcy1 as well as EpoR. This result is in line with previous studies in murine erythroblasts, demonstrating that EpoR, Plcy1, TRPC2 and $I_{3} R$ associate to form a signaling complex. ${ }^{19}$ Our data show very rapid and Actinomycin D-independent phosphorylation of $\mathrm{Plc} \gamma 1$ upon Epo stimulation (1 $\mathrm{min})$. Together, these results strongly suggest direct activation of $\mathrm{Plc} \gamma 1$ upon EpoR stimulation.

So far, a role of Plc 1 signaling has been only described in primitive erythropoiesis of the yolk sac in mouse and zebrafish. $^{11,14}$ Primitive erythropoiesis is not exclusively 
dependent on Epo, ${ }^{38,39}$ whereas fetal liver and adult erythropoiesis is critically regulated by Epo-EpoR signaling. ${ }^{4,24}$ As $\mathrm{Plc} 1$ is activated downstream of EpoR-Jak2 in $1 / 11$ proerythroblasts, we focused on its role in terminal erythroid differentiation.

Stimulation of the Epo receptor leads to rapid activation of intracellular signaling pathways including that of the transcription factor Stat5, ${ }^{17}$ which has a strong antiapoptotic effect in erythroid cells. ${ }^{6,7}$ The promoting role of Stat5 in fetal liver and adult erythropoiesis is well recognized but remains partly controversial because of different phenotypes of Stat5deficient mouse models. ${ }^{6,7,40-42}$ Owing to the fact that lack of Stat5 proteins resulted in a less severe erythroid phenotype than shown by $\mathrm{EpoR}^{-/-}$or Jak2 ${ }^{-/-}$mice, it appears that additional signaling pathways are involved in Epo-EpoRJak2-induced differentiation of erythroid progenitors. To this end, our experiments have now demonstrated an essential role of $P l c \gamma 1$ in the regulation of erythroid development. Interestingly, knockdown of Plc $\gamma 1$ did not affect the phosphorylation of Stat5, however, erythroid differentiation was impaired. This identifies a novel and previously unknown Stat5-independent pathway mediating erythroid differentiation through $\mathrm{Plc} \gamma 1$ and $\mathrm{mH} 2 \mathrm{~A} 2$. These findings are in line with reports from other groups showing that Jak2 signaling is a key component of early erythroid development and fetal liver erythropoiesis. ${ }^{43,44}$

To gain a deeper insight into the role of $\mathrm{Plc} 1$ in the process of erythroid commitment, we performed gene expression analysis on $\mathrm{l} / 11$ erythroid progenitor cells transduced with either Plc 1 or control shRNAs at different time points after induction of differentiation. Owing to the fact that several epigenetic regulators were affected in Plcy1-deficient cells during differentiation (e.g. Hist2h2be, H2afy2), we decided to screen for epigenetic changes by performing a global methylome analysis. Applying MCIP-seq screening, we found a limited number of consistent DNA methylation changes. We assume that this is mainly because of the fact that the time points chosen for methylome analysis did not allow for the development of major DNA methylation changes. This is further supported by the fact that the observed DNA methylation changes were of moderate degree. Therefore, we decided to perform a promoter and CGI-centric analysis in order to focus on well-annotated gene-regulatory regions. Most DNA methylation changes observed here were characterized by a loss of methylation following Plc 1 knockdown. This pattern may reflect a more undifferentiated state because of the observed impairment in erythroid differentiation upon Plcy1 knockdown and indicates that control cells undergoing erythroid differentiation are mainly characterized by an increase of methylation at promoters and CGIs. This finding is in line with other studies using genome-wide methylation analyses along hematopoietic differentiation, which have shown a gradual gain of methylation during the hematopoietic differentiation process. ${ }^{45}$ We identified H2afy2 as the top candidate target gene that was found to be both differentially methylated and among the top differentially expressed genes. Although, in this case, lower methylation levels correlated with lower gene expression levels for H2afy2, this observation is fully compatible with findings from other studies comparing gene expression levels and methylation levels on the global scale, where the classical anti-correlation can be observed on average, while there are also many DMRs that seem to be positively correlated with gene expression. ${ }^{45,46}$ Another possible explanation for this observation would be that the promoter hypomethylation of H2afy2 is a secondary adaptive effect by which the cells try to counteract the Plc $\gamma 1$-associated downregulation of $\mathrm{H} 2$ afy 2 by hypomethylation of the promoter region, which then actually leads to a more transcriptionally permissive promoter state. The H2afy2 gene encodes for the histone variant $\mathrm{mH} 2 \mathrm{~A} 2$. Expression levels of macroH2A proteins correlate with the state of differentiation. ${ }^{31,32}$ Loss of function approaches revealed a critical role for these histone variants in the differentiation but not the self-renewal of embryonic and adult stem cells. ${ }^{34}$ Although macroH2As have well-characterized repressive functions, their influence on differentiation of embryonic stem cells is at least in part dependent on a pro-activating function of macroH2A1 on important differentiation regulatory genes such as Gata2 and Brachyury. ${ }^{34}$ In line with the proposed pro-differentiation function of macroH2A, knockdown of $\mathrm{mH}_{2} \mathrm{~A} 2$ in proerythroblasts resulted in delayed erythroid maturation after Epo stimulation. These data resemble almost identically the morphological and immunophenotypical differentiation process of Plcy1-deficient cells as shown before. As knockdown of $\mathrm{mH} 2 \mathrm{~A} 2$ did not alter survival, cell cycle distribution and proliferation of erythroid cells, our results suggest a direct influence of $\mathrm{mH} 2 \mathrm{~A} 2$ on erythroid differentiation. At present, virtually nothing is known about how the incorporation of $\mathrm{mH} 2 \mathrm{~A}$ into the nucleosomes is regulated.

Taken together, our findings dissect the molecular processes involved in differentiation and proliferation, and disconnects differentiation from Stat5-mediated effects such as cell survival, cell cycle and proliferation. These results provide first evidence that Plcy1 signaling serves as a 'noncanonical' pathway essential for developmental erythropoiesis in fetal liver and adult erythropoiesis. This novel pathway is activated by Epo-EpoR-Jak2 and regulates the expression of the downstream target $\mathrm{mH}_{2} \mathrm{~A} 2$, which contributes to the execution of the erythropoietic differentiation process.

\section{Materials and Methods}

Cell culture. Ba/F3 and 32D cells were cultured in RPMI 1640 medium (PAA, Cölbe, Germany) supplemented with $10 \%$ FBS (PAA) in a humid atmosphere of $5 \%$ $\mathrm{CO}_{2}$ at $37^{\circ} \mathrm{C}$. FLCs were cultured in StemSpan SFEM medium (Stemcell Technologies, Köln, Germany) supplemented with cytokines (100 ng/ml SCF, $10 \mathrm{ng} /$ $\mathrm{ml} \mathrm{TPO}, 6 \mathrm{ng} / \mathrm{ml} \mathrm{IL-3}$ and $10 \mathrm{ng} / \mathrm{ml} \mathrm{IL-6)}$. The expanding erythroid progenitors (I/11) were maintained in serum-free medium (StemPro 34 plus nutrient supplement, Life Technologies, Darmstadt, Germany) supplemented with $1 \mathrm{U} / \mathrm{ml}$ of human recombinant Epo (Janssen-Cilag, Neuss, Germany), $100 \mathrm{ng} / \mathrm{ml}$ SCF (PeproTech, Hamburg, Germany), $1 \mu \mathrm{M}$ dexamethasone (Sigma-Aldrich, Munich, Germany) and $1 \%$ penicillin/streptomycin (Life Technologies). For differentiation induction, $1 / 11$ and lineage-depleted BM cells were seeded in StemPro34 medium containing $10 \mathrm{U} / \mathrm{ml}$ Epo, $\quad 0.5 \mathrm{mg} / \mathrm{ml}$ human holo-transferrin (Sigma-Aldrich) and $1 \%$ penicillin/ streptomycin (Life Technologies).

Cellular proliferation. $1 / 11$ cells stably infected with either control or Plc $\gamma 1$ shRNA were seeded in triplicate into 96 -well plates at a density of $5 \times 10^{3}$ per well. Epo was added in different concentrations and the plates were incubated for $72 \mathrm{~h}$ at $37^{\circ} \mathrm{C}$. Wells with medium (RPMl $1640,10 \% \mathrm{FBS}$ ) were used as negative control. For the MTS assay, the CellTiter 96 AQueous Non-Radioactive Cell Proliferation Assay Kit (Promega, Madison, WI, USA) was used following the manufacturer's instruction. 
Apoptosis assay. 1/11 cells stably infected with either control or specific shRNA were seeded in a six-well plates at a density of $5 \times 10^{4} / \mathrm{ml}$ per well (day 7 post-infection). Apoptosis of cells was measured by flow cytometry for 2 days (24 and $48 \mathrm{~h}$ ) using Annexin V/SYTOX Blue (Life Technologies) staining following the manufacturer's instruction.

Cell cycle assay. Cell cycle distribution of $I / 11$ cells stably infected with either control or specific shRNA was measured by flow cytometry using Ki-67 staining. Briefly, 7 days post-infection cells were seeded in a six-well plates at a density of $5 \times 10^{4} / \mathrm{ml}$ per well and cell cycle was measured after 24,48 and $72 \mathrm{~h}$.

Isolation, lineage depletion and infection of BM cells. All mice were housed under pathogen-free conditions in the accredited Animal Research Facility of the Otto-von-Guericke University Medical Faculty, Magdeburg, Germany. All experiments were conducted after approval by the Landesverwaltungsamt SaxonyAnhalt. Bones were dissected from humanely killed 8- to 12-week-old C57BL/6 mice (Janvier S.A.S., St. Berthevin Cedex, France) and BM was isolated following standard procedures. Lineage depletion was performed as described before. ${ }^{47}$ Lineage depletion was performed using Dynabeads M-280 Streptavidin and a Dynal magnet (Life Technologies). Lineage-depleted cells were infected twice with lentiviral particles (by spinfection; 2000 r.p.m. for $1.5 \mathrm{~h}$ at $33^{\circ} \mathrm{C}$ ) containing scrambled or Plc 1 -specific shRNAs. Cells were cultured in virus medium supplemented with cytokines for $24 \mathrm{~h}$ and were set on differentiation medium, followed by selection with puromycin ( $1 \mu \mathrm{g} / \mathrm{ml}$, Applichem, Darmstadt, Germany).

Isolation and infection of FLCs. FLC were harvested from embryos of C57BL/6 mice at day E13.5. FLC were cultured in a six-well plate $\left(1 \times 10^{6}\right.$ per well) in serum-free medium (SFEM, Stemcell Technologies) supplemented with $100 \mathrm{ng} / \mathrm{ml}$ SCF, $10 \mathrm{ng} / \mathrm{ml} \mathrm{TPO}, 6 \mathrm{ng} / \mathrm{ml} \mathrm{IL}-3$ and $10 \mathrm{ng} / \mathrm{ml} \mathrm{IL-} 6$ (PeproTech) over night and then infected with lentiviral particles (by spinfection; 2000 r.p.m. for $2 \mathrm{~h}$ at $33^{\circ} \mathrm{C}$ ) containing control or Plc $\gamma 1$-specific shRNAs. After $24 \mathrm{~h}$, infection cells were cultured in SFEM medium supplemented with cytokines for $24 \mathrm{~h}$, followed by selection with puromycin $(1 \mu \mathrm{g} / \mathrm{ml})$ for $48 \mathrm{~h}$.

Methylcellulose colony formation assay. For investigation of colony formation in methylcellulose, FLC or lineage-depleted BM cells, respectively, infected with either control or Plc $\gamma 1$-specific shRNA were seeded in MethoCult GF M3434 (Stem Cell Technologies) at different concentrations (BM cells: 1000 cells; FLC: $2000 / 10000$ cells). I/11 cells infected with either control or PIc $\gamma 1$-specific shRNA were plated at a concentration of 1000 cells in MethoCult GF M3236 (Stem Cell Technologies) supplemented with $1 \mathrm{U} / \mathrm{ml}$ Epo and $0.5 \mathrm{mg} / \mathrm{ml}$ human holotransferrin (Sigma-Aldrich). Colony numbers were counted on day 10 after plating.

Competitive repopulation assay. Immunophenotypically defined HSC ( Lin $^{-} \mathrm{Sca1}^{+} \mathrm{KIT}^{+} \mathrm{CD} 48^{-} \mathrm{CD} 150^{+}$) derived from Ly45.1/2 (CD45.1/2) donor mice were sorted and pre-stimulated with cytokines $(100 \mathrm{ng} / \mathrm{ml} \mathrm{SCF}, 10 \mathrm{ng} / \mathrm{ml} \mathrm{TPO}, 6 \mathrm{ng} / \mathrm{ml}$ $\mathrm{IL}-3,10 \mathrm{ng} / \mathrm{ml} \mathrm{IL-} 6$ and $60 \mathrm{ng} / \mathrm{ml} \mathrm{G-CSF}$ ). Twelve hours after stimulation, HSCs were infected twice with PIc $\gamma 1$ shRNA or control shRNA (both cloned into a pLKO.1GFP vector). Forty-eight hours after infection, $500 \mathrm{GFP}^{+} \mathrm{CD} 45.1 / 2$ cells were injected along with $2.5 \times 10^{5} \mathrm{CD} 45.2$ (whole BM) cells into lethally irradiated CD45.2 recipient mice ( $13 \mathrm{~Gy}$, single dose). Twenty weeks after transplant, the mice were killed and BM was evaluated as described previously. ${ }^{48}$

Flow cytometry and antibody staining. The antibodies used for cell surface staining are described in Supplementary Table S1. Cells were stained in PBS $/ 1 \%$ FBS for $1.5 \mathrm{~h}$ at $4{ }^{\circ} \mathrm{C}$. SYTOX Blue Dead Cell Stain (Life Technologies) was used to exclude dead cells. Flow cytometry was performed on a FACS Canto II cytometer (Becton Dickinson, Heidelberg, Germany). For DNA content analysis (propidiumiodide staining), cells were harvested, resuspended in $300 \mu \mathrm{l} \mathrm{HFS-buffer}$ $(0.05 \mathrm{mg} / \mathrm{ml}$ propidiumiodide, $1 \mathrm{mg} / \mathrm{ml}$ sodium-citrate, $1 \mu \mathrm{l} / \mathrm{ml}$ Triton X-100) and then subjected to FACS analysis. Intracellular staining of Plc $\gamma 1$ and cell cycle analysis with Ki-67 were performed using the Fix \& Perm Cell Permeabilization Kit (Life Technologies) following the manufacturer's instruction. The following antibodies were used for intracellular PIc $\gamma 1$ detection: anti-PIc $\gamma 1$ antibody (3634-1, Abcam, Cambridge, UK), DyLight 649 donkey anti-rabbit lgG (406406, Biolegend, San Diego, CA, USA).

Immunoblotting and immunoprecipitation. $\mathrm{Ba} / \mathrm{F} 3$ and $32 \mathrm{D}$ cells expressing EpoR and wild-type Jak2 or Jak-2V617F were washed twice with
PBS and starved for $4 \mathrm{~h}$ in serum-reduced $(0.5 \%)$ medium at a density of $1 \times 10^{6} / \mathrm{ml}$. Cells were treated with or without JAK inhibitor I (30 min), LY292004 (1 h), U0126 ( $1 \mathrm{~h}$; all Calbiochem, Darmstadt, Germany) and Actinomycin D ( $2 \mathrm{~h}$; Santa Cruz Biotechnologies, Dallas, TX, USA), respectively. Cells were re-stimulated with $3 \mathrm{U} / \mathrm{ml}$ Epo for $10 \mathrm{~min}$ and lysed as described previously. ${ }^{49} \mathrm{l} / 11$ cells were starved for $4 \mathrm{~h}$ in serum-free medium without Epo, SCF and dexamethasone, treated with inhibitor and then re- stimulated with $3 \mathrm{U} / \mathrm{ml}$ Epo for $10 \mathrm{~min}$ before lysis. For immunoprecipitation, the TrueBlot Anti-Rabbit Ig IP Beads Kit (Rockland Immunochemicals, Gilbertsville, PA, USA) was used following the manufacturer's instruction. The following antibodies were purchased from Cell Signaling (Danvers, MA, USA) and used at a 1:1000 dilution: p- Plc 1 (2821), Plc 1 (2822), p-Mek (9154), Mek (4694), p-Akt (9271), Akt (9272), p-p44/42 MAPK (9106) and p44/42 MAPK (9102). GAPDH antibody (H86504M, 1: 5000) was purchased from Meridian Life Sciences (Memphis, TN, USA), p-Stat5 antibody (05-495, 1:1000) was purchased from Millipore (Darmstadt, Germany) and Stat5 (sc-1081, 1:100) antibody was purchased from Santa Cruz Biotechnologies.

RNAi. siRNAs from Plc $\gamma 1$ siGENOME SMART Pool (M-040978-01-0005, Dharmacon, Schwerte, Germany) or AllStars Negative siRNA AF488 (Life Technologies) were transfected at a concentration of $2 \mu \mathrm{M} / \mathrm{million}$ cells by microporation ( $1700 \mathrm{~V}, 30 \mathrm{~ms}, 1$ impuls). For Plc $\gamma 1$ shRNA knockdown experiments, pLKO vector system with puromycin resistance gene or GFP was used containing different shRNA sequences for Plc $\gamma 1$ (RNAi Consortium Broad Range Institutes, Harvard University, Boston, MA, USA; or Sigma-Aldrich). For mH2A2 knockdown experiments, pLKO vector system with puromycin resistance gene was used containing different shRNA sequences for mH2A2 (Sigma-Aldrich; M. Buschbeck, IMPPC, Badalona, Spain). HEK293T cells were transfected using FUGENE HD Transfection Reagent (Roche, Mannheim, Germany) to generate lentiviral particles. The knockdown efficiency was assessed by GPCR after infection of the respective cells.

Quantitative real-time PCR. Equal amounts $(1 \mu \mathrm{g})$ of total RNA extracted using TRIzol reagent (Life Technologies) were reverse-transcribed using Omniscript RT Kit (Qiagen, Hilden, Germany) as per the manufacturer's instructions and complementary DNA samples were analyzed by qPCR using inventoried TaqMan gene expression assays (Life Technologies; Gapdh Mm99999915_g1; PIc $\gamma 1$ Mm01247267_g1; H2afy2 Mm02584514_s1). For each analysis, three separate experiments were performed, and each qPCR was run in triplicate and normalized to Gapdh.

For gene expression analysis in Plcy1-deficient cells, qPCR was performed using SYBR Premix Ex Taq II Kit (Clontech Laboratories, Mountain View, CA, USA). Genespecific primers were designed to span exon-exon boundaries to avoid amplification of genomic DNA. All expression values were normalized to $\beta$-actin and samples were run in triplicate. Quantitative PCR data were normalized and standardized with Bio-Rad CFX Manager software (Munich, Germany). Primer sequences: $\beta$-actin for (5'-AGAGAGGTATCCTGACCCTGAAGT-3'), $\beta$-actin rev (5'-CACGCAGCTCATTG TAGAAGGTGT-3'), Plc $\gamma 1$ for (5'-GTTTGTAGTGGACAACGGACTG-3'), Plc $\gamma 1$ rev (5'-CTATATCCTGTCTTCAGGCC-3').

Giemsa staining. To analyze cell morphology, $2 \times 10^{5}$ cells were centrifuged onto slides and stained as described previously. ${ }^{50}$

Gene expression profiling and microarray analysis. For gene expression analysis, $1 / 11$ cells were infected with lentiviral particles (by spinfection; 2000 r.p.m. for $1.5 \mathrm{~h}$ at $33^{\circ} \mathrm{C}$ ) containing either control or Plc $\gamma 1$-specific shRNAs. After $24 \mathrm{~h}$ of infection, cells were cultured in serum-free medium (StemPro 34, Life Technologies) supplemented with $1 \mathrm{U} / \mathrm{ml}$ of human recombinant Epo (JanssenCilag), $100 \mathrm{ng} / \mathrm{ml}$ SCF (PeproTech), $1 \mu \mathrm{M}$ dexamethasone (Sigma-Aldrich) and 1\% penicillin/streptomycin (Life Technologies) for $24 \mathrm{~h}$, followed by selection with puromycin $(1 \mu \mathrm{g} / \mathrm{ml})$ for $48 \mathrm{~h}$. For differentiation induction, $1 / 11$ cells were seeded $72 \mathrm{~h}$ after infection in StemPro 34 medium containing $10 \mathrm{U} / \mathrm{ml}$ Epo, $0.5 \mathrm{mg} / \mathrm{ml}$ human holo-transferrin (Sigma-Aldrich) and $1 \%$ penicillin/streptomycin (Life Technologies). Cells were harvested at the indicated time points and RNA was isolated from $5 \times 10^{5} \mathrm{I} / 11$ cells transfected with either scrambled or PLC $\gamma 1$ shRNA using TRIzol (Life Technologies). RNA was amplified using the Ovation Pico WTA system and labeled using the encore Biotin Module (both Nugen, San Carlos, CA, USA). Five microgram of amplified and labeled DNA was hybridized to Affymetrix GeneChip Mouse Genome 430plus 2.0 microarrays according to the manufacturer's recommendations (Affymetrix, Santa Clara, CA, USA). The complete microarray 
data are available at the Gene Expression Omnibus (http://www.ncbi.nlm.nih.gov/ projects/geo; accession number GSE54223).

In brief, fluorescence ratios were normalized by applying the Robust Multiarray Averaging algorithm using the BRB Array Tools software package (available at http:// linus.nci.nih.gov/BRB-ArrayTools.html). For subsequent analyses, we only included probe sets $(n=10078)$ whose expression varied as previously determined (genes with a log intensity variation of $P>0.01$ were excluded).$^{51}$ For the comparison of scrambled versus Plc $\gamma 1$ shRNA-treated cell lines, supervised analysis was carried out as previously reported (for Class Comparison Analysis the nominal significance level of each univariate test (two-sample $t$-test with random variance model) was $P<0.05$ ). ${ }^{52}$ Results were visualized using TreeView Software (University of California, Berkeley, CA, USA; http://www.eisenlab.org/eisen/?page_id=42).

\section{Enrichment of DNA using Methyl-CpG immunoprecipitation} followed by next-generation sequencing. For methylome analysis, $1 / 11$ cells were treated similar to the gene expression analysis as described before. We used methyl-CpG immunoprecipitation followed by next-generation sequencing as described earlier. ${ }^{5,53}$ In brief, $3 \mu \mathrm{g}$ of genomic DNA were sonicated in a Covaris S sonicator (Covaris Inc., Woburn, MA, USA). DNA fragments, which were about $150 \mathrm{bp}$ in size, were then subjected to enrichment with $60 \mu \mathrm{g}$ MBD2-Fc protein in the presence of a sodium chloride gradient (fraction A: $300 \mathrm{mM}$; B: $400 \mathrm{mM}$; C: $500 \mathrm{mM}$; D: $550 \mathrm{mM}$; E: 1,000 mM). For this procedure, we used a SX-8G IP-Star robot (Diagenode, Liege, Belgium) using a standard protocol as described elsewhere. ${ }^{5}$ Desalting of eluates was performed using MinElute columns (Qiagen). Enrichment efficiency of methylated DNA was checked by qPCR using primers for the imprinted gene Mest. Primer sequences are as follows: Mest-F: 5'-CAGACGCCACCTCCGATCC-3', Mest-R: 5'-GGCCGCATTATCCCATGCC-3'. The un-methylated Mest allele shows no enrichment (i.e., it is found in the low salt fraction), whereas the methylated allele shows enrichment in the final (high salt) eluate. The DNA fractions highly enriched for methylated DNA (eluted with $1 \mathrm{M}$ $\mathrm{NaCl}$, fraction $\mathrm{E}$ ) were subjected to next-generation sequencing. The sequencing libraries were prepared using the NebNext chemistry (New England Biolabs, Ipswich, MA, USA) according to the manufacturer's recommendations. Libraries were sequenced on an Illumina HiSeq 2000 (Illumina Inc., San Diego, CA, USA) using the $50 \mathrm{bp}$ single-end mode. Raw reads were mapped to the mouse reference genome (mm10) using the BWA aligner, and subsequently duplicates and lowquality reads (MAQ score $<20$ ) were removed using SAMtools. The MEDIPS package was used to calculate the saturation coefficient as a measure for sufficient read depth of all regions that can be captured by MCIP. In this study, all samples showed a saturation coefficient of $\geq 0.96$. DMRs between samples were detected genome-wide using the Homer software package (http://biowhat.ucsd.edu/homer) ${ }^{54}$ For peak calling, we used a fixed peak size of $150 \mathrm{bp}$ and otherwise default settings. The terms hyper- and hypomethylated DMRs always refer to the Plc $\gamma 1$ knockdown samples as compared with the scr shRNA knockdown samples. Genomic annotation was performed with BEDtools (http://bedtools.googlecode.com) using standard region definitions as obtained from the USCS genome browser (http:// genome.ucsc.edu/). The complete methylome analysis is available at the Gene Expression Omnibus (http://www.ncbi.nlm.nih.gov/projects/geo; accession number GSE60087). Gene ontology analysis was performed using the DAVID functional annotation tool (http://david.abcc.ncifcrf.gov/home.jsp). ${ }^{55,56}$

Quantitative high-resolution DNA methylation analysis. To validate DMRs detected by MCIP-Seq, DNA methylation levels for selected DMRs were assessed quantitatively using the MassArray system as described previously (primer sequences are provided in Supplementary Table S5). ${ }^{31,57}$ Analysis of methylation profiles was done using the EpiTYPER software (Sequenom, San Diego, CA, USA) and visualization of methylation values was performed using MultiExperimentViewer (http://www.tm4.org/mev/).

Statistical analysis. Graphs were analyzed using GraphPad Prism Version 5.0b (GraphPad Software Inc., La Jolla, CA, USA). Statistical significance was determined using Mann-Whitney U-test (when normal distribution was not given) or two-way ANOVA. A P-value below 0.05 was considered significant. Where no $P$-value is indicated through stars, no statistically significant difference was found. ${ }^{\star} P<0.05$, ${ }^{\star \star} P<0.01,{ }^{\star \star \star} P<0.001$. Flow cytometry data were analyzed with FlowJo software (Treestar Inc., Ashland, OR, USA).

\section{Conflict of Interest}

The authors declare no conflict of interest.
Acknowledgements. We thank Uta Schönborn, Stephi Frey and Sönke Weinert (Otto-von-Guericke University, Magdeburg, Germany) for technical assistance. We thank $\mathrm{Dr}$ Andreas Fenske, (Otto-von-Guericke University, Magdeburg, Germany) for support with the mouse experiments and Dr Roland Hartig (Otto-von-Guericke University, Magdeburg, Germany) for his support with cell sorting. We thank Marieke von Lindern (Erasmus University, Rotterdam) for providing 1/11 parental cells. This project was supported by a grant from the German Research Council (DFG; SFB854, TP20, 2010-2013 to TF and 2014-2017 to TF and FHH), in part by grants from the Jose-Carreras-Foundation (DJCLS F 12/06 to FHH and PA-T; SP 12/04 to FHH, in support of the Hematology Tumor Bank Magdeburg) and by the German Ministry of Education and Research (BMBF; e.bio JAK-Sys to TF).

1. Richmond TD, Chohan M, Barber DL. Turning cells red: signal transduction mediated by erythropoietin. Trends Cell Biol 2005; 15: 146-155.

2. Paulson RF, Bernstein A. Receptor tyrosine kinases and the regulation of hematopoiesis. Semin Immunol 1995; 7: 267-277.

3. Cantor AB, Orkin SH. Hematopoietic development: a balancing act. Curr Opin Genet Dev 2001; 11: 513-519.

4. Wu H, Liu X, Jaenisch R, Lodish HF. Generation of committed erythroid BFU-E and CFU-E progenitors does not require erythropoietin or the erythropoietin receptor. Cell 1995; 83: 59-67.

5. Grebien F, Kerenyi MA, Kovacic B, Kolbe T, Becker V, Dolznig H et al. Stat5 activation enables erythropoiesis in the absence of EpoR and Jak2. Blood 2008; 111: 4511-4522.

6. Socolovsky M, Fallon AE, Wang S, Brugnara C, Lodish HF. Fetal anemia and apoptosis of red cell progenitors in Stat5a-/-5b-/- mice: a direct role for Stat5 in $\mathrm{Bcl}-\mathrm{X}(\mathrm{L})$ induction. Cell 1999; 98: 181-191.

7. Socolovsky M, Nam H, Fleming MD, Haase VH, Brugnara C, Lodish HF. Ineffective erythropoiesis in Stat5a(-/-)5b(-/-) mice due to decreased survival of early erythroblasts. Blood 2001; 98: 3261-3273.

8. Klingmuller U, Wu H, Hsiao JG, Toker A, Duckworth BC, Cantley LC et al. Identification of a novel pathway important for proliferation and differentiation of primary erythroid progenitors. Proc Natl Acad Sci USA 1997; 94: 3016-3021.

9. Socolovsky M, Dusanter-Fourt I, Lodish HF. The prolactin receptor and severely truncated erythropoietin receptors support differentiation of erythroid progenitors. J Biol Chem 1997; 272: 14009-14012.

10. Wu H, Klingmuller U, Acurio A, Hsiao JG, Lodish HF. Functional interaction of erythropoietin and stem cell factor receptors is essential for erythroid colony formation. Proc Natl Acad Sci USA 1997; 94: 1806-1810.

11. Liao HJ, Kume T, McKay C, Xu MJ, Ihle JN, Carpenter G. Absence of erythrogenesis and vasculogenesis in Plcg1-deficient mice. J Biol Chem 2002; 277: 9335-9341.

12. Markova B, Albers C, Breitenbuecher F, Melo JV, Brummendorf TH, Heidel F et al. Novel pathway in Bcr-Abl signal transduction involves Akt-independent, PLC-gamma1-driven activation of mTOR/p70S6-kinase pathway. Oncogene 2010; 29: 739-751.

13. Ji QS, Winnier GE, Niswender KD, Horstman D, Wisdom R, Magnuson MA et al. Essential role of the tyrosine kinase substrate phospholipase C-gamma1 in mammalian growth and development. Proc Natl Acad Sci USA 1997; 94: 2999-3003.

14. Ma AC, Liang R, Leung AY. The role of phospholipase $C$ gamma 1 in primitive hematopoiesis during zebrafish development. Exp Hematol 2007; 35: 368-373.

15. Kim JW, Sim SS, Kim UH, Nishibe S, Wahl MI, Carpenter G et al. Tyrosine residues in bovine phospholipase $\mathrm{C}$-gamma phosphorylated by the epidermal growth factor receptor in vitro. J Biol Chem 1990; 265: 3940-3943.

16. Irvin BJ, Williams BL, Nilson AE, Maynor HO, Abraham RT. Pleiotropic contributions of phospholipase C-gamma1 (PLC-gamma1) to T-cell antigen receptor-mediated signaling: reconstitution studies of a PLC-gamma1-deficient Jurkat T-cell line. Mol Cell Biol 2000; 20: 9149-9161.

17. von Lindern M, Schmidt U, Beug H. Control of erythropoiesis by erythropoietin and stem cell factor: a novel role for Bruton's tyrosine kinase. Cell Cycle 2004; 3: 876-879.

18. Halupa A, Chohan M, Stickle NH, Beattie BK, Miller BA, Barber DL. Erythropoietin receptor Y479 couples to ERK1/2 activation via recruitment of phospholipase Cgamma. Exp Cell Res 2005; 309: 1-11.

19. Tong Q, Chu X, Cheung JY, Conrad K, Stahl R, Barber DL et al. Erythropoietin-modulated calcium influx through TRPC2 is mediated by phospholipase Cgamma and IP3R. Am J Physiol Cell Physiol 2004; 287: C1667-C1678.

20. Ihle JN. Signaling by the cytokine receptor superfamily in normal and transformed hematopoietic cells. Adv Cancer Res 1996; 68: 23-65.

21. Leevers SJ, Vanhaesebroeck B, Waterfield MD. Signalling through phosphoinositide 3-kinases: the lipids take centre stage. Curr Opin Cell Biol 1999; 11: 219-225.

22. Haq R, Halupa A, Beattie BK, Mason JM, Zanke BW, Barber DL. Regulation of erythropoietin-induced STAT serine phosphorylation by distinct mitogen-activated protein kinases. J Biol Chem 2002; 277: 17359-17366.

23. Chen K, Liu J, Heck S, Chasis JA, An X, Mohandas N. Resolving the distinct stages in erythroid differentiation based on dynamic changes in membrane protein expression during erythropoiesis. Proc Natl Acad Sci USA 2009; 106: 17413-17418. 
24. Lin CS, Lim SK, D'Agati V, Costantini F. Differential effects of an erythropoietin receptor gene disruption on primitive and definitive erythropoiesis. Genes Dev 1996; 10: 154-164.

25. McGrath K, Palis J. Ontogeny of erythropoiesis in the mammalian embryo. Curr Top Dev Biol 2008; 82: 1-22.

26. He S, Kim I, Lim MS, Morrison SJ. Sox17 expression confers self-renewal potential and fetal stem cell characteristics upon adult hematopoietic progenitors. Genes Dev 2011; 25: 1613-1627.

27. Kim I, Saunders TL, Morrison SJ. Sox17 dependence distinguishes the transcriptional regulation of fetal from adult hematopoietic stem cells. Cell 2007; 130: 470-483.

28. Braiman A, Barda-Saad M, Sommers CL, Samelson LE. Recruitment and activation of PLCgamma1 in T cells: a new insight into old domains. EMBO J 2006; 25: 774-784.

29. Weiss A, Koretzky G, Schatzman RC, Kadlecek T. Functional activation of the T-cell antigen receptor induces tyrosine phosphorylation of phospholipase C-gamma 1. Proc Natl Acad Sci USA 1991; 88: 5484-5488.

30. Buschbeck M, Di Croce L. Approaching the molecular and physiological function of macroH2A variants. Epigenetics 2010; 5: 118-123.

31. Dai B, Rasmussen TP. Global epiproteomic signatures distinguish embryonic stem cells from differentiated cells. Stem Cells 2007; 25: 2567-2574.

32. Pehrson JR, Costanzi C, Dharia C. Developmental and tissue expression patterns of histone macroH2A1 subtypes. J Cell Biochem 1997; 65: 107-113.

33. Buschbeck M, Uribesalgo I, Wibowo I, Rue P, Martin D, Gutierrez A et al. The histone variant macroH2A is an epigenetic regulator of key developmental genes. Nat Struct Mol Biol 2009; 16: 1074-1079.

34. Creppe C, Janich P, Cantarino N, Noguera M, Valero V, Musulen E et al. MacroH2A1 regulates the balance between self-renewal and differentiation commitment in embryonic and adult stem cells. Mol Cell Biol 2012; 32: 1442-1452.

35. Pasque V, Radzisheuskaya A, Gillich A, Halley-Stott RP, Panamarova M, Zernicka-Goetz M et al. Histone variant macroH2A marks embryonic differentiation in vivo and acts as an epigenetic barrier to induced pluripotency. J Cell Sci 2012; 125: 6094-6104.

36. Wilde JI, Watson SP. Regulation of phospholipase C gamma isoforms in haematopoietic cells: why one, not the other? Cell Signal 2001; 13: 691-701.

37. Choi JH, Kim HS, Kim SH, Yang YR, Bae YS, Chang JS et al. Phospholipase Cgamma1 negatively regulates growth hormone signalling by forming a ternary complex with Jak2 and protein tyrosine phosphatase-1B. Nat Cell Biol 2006; 8: 1389-1397.

38. Dzierzak E, Medvinsky A. Mouse embryonic hematopoiesis. Trends Genet 1995; 11 : 359-366

39. Sasaki R, Masuda S, Nagao M. Erythropoietin: multiple physiological functions and regulation of biosynthesis. Biosci Biotechnol Biochem 2000; 64: 1775-1793.

40. Cui Y, Riedlinger G, Miyoshi K, Tang W, Li C, Deng CX et al. Inactivation of Stat5 in mouse mammary epithelium during pregnancy reveals distinct functions in cell proliferation, survival, and differentiation. Mol Cell Biol 2004; 24: 8037-8047.

41. Engblom D, Kornfeld JW, Schwake L, Tronche F, Reimann A, Beug H et al. Direct glucocorticoid receptor-Stat5 interaction in hepatocytes controls body size and maturationrelated gene expression. Genes Dev 2007; 21: 1157-1162.
42. Teglund S, McKay C, Schuetz E, van Deursen JM, Stravopodis D, Wang D et al. Stat5a and Stat5b proteins have essential and nonessential, or redundant, roles in cytokine responses. Cell 1998; 93: 841-850.

43. Neubauer $\mathrm{H}$, Cumano A, Muller M, Wu H, Huffstadt U, Pfeffer K. Jak2 deficiency defines an essential developmental checkpoint in definitive hematopoiesis. Cell 1998; 93: 397-409.

44. Parganas E, Wang D, Stravopodis D, Topham DJ, Marine JC, Teglund S et al. Jak2 is essential for signaling through a variety of cytokine receptors. Cell 1998; 93 : 385-395.

45. Cabezas-Wallscheid N, Klimmeck D, Hansson J, Lipka DB, Reyes A, Wang Q et al. Identification of regulatory networks in HSCs and their immediate progeny via integrated proteome, transcriptome, and DNA methylome analysis. Cell Stem Cell 2014; 15: 507-522.

46. Bock C, Beerman I, Lien WH, Smith ZD, Gu H, Boyle P et al. DNA methylation dynamics during in vivo differentiation of blood and skin stem cells. Mol Cell 2012; 47: 633-647.

47. Heidel FH, Bullinger L, Feng Z, Wang Z, Neff TA, Stein L et al. Genetic and pharmacologic inhibition of beta-catenin targets imatinib-resistant leukemia stem cells in CML. Cell Stem Cell 2012; 10: 412-424.

48. Heidel FH, Bullinger L, Arreba-Tutusaus P, Wang Z, Gaebel J, Hirt C et al. The cell fate determinant Llgl1 influences HSC fitness and prognosis in AML. J Exp Med 2013; 210: 15-22.

49. Kindler T, Breitenbuecher F, Kasper S, Stevens T, Carius B, Gschaidmeier H et al. In BCRABL-positive cells, STAT-5 tyrosine-phosphorylation integrates signals induced by imatinib mesylate and Ara-C. Leukemia 2003; 17: 999-1009.

50. Beug H, Doederlein G, Freudenstein C, Graf T. Erythroblast cell lines transformed by a temperature-sensitive mutant of avian erythroblastosis virus: a model system to study erythroid differentiation in vitro. J Cell Physiol Suppl 1982; 1: 195-207.

51. Sander S, Calado DP, Srinivasan L, Kochert K, Zhang B, Rosolowski M et al. Synergy between PI3K signaling and MYC in Burkitt lymphomagenesis. Cancer Cell 2012; 22: 167-179.

52. Luck SC, Russ AC, Botzenhardt U, Paschka P, Schlenk RF, Dohner H et al. Deregulated apoptosis signaling in core-binding factor leukemia differentiates clinically relevant, molecular marker-independent subgroups. Leukemia 2011; 25: 1728-1738.

53. Sonnet M, Baer C, Rehli M, Weichenhan D, Plass $C$. Enrichment of methylated DNA by methyl-CpG immunoprecipitation. Methods Mol Biol 2013; 971: 201-212.

54. Heinz S, Benner C, Spann N, Bertolino E, Lin YC, Laslo P et al. Simple combinations of lineage-determining transcription factors prime cis-regulatory elements required for macrophage and B cell identities. Mol Cell 2010; 38: 576-589.

55. Huang da W, Sherman BT, Lempicki RA. Systematic and integrative analysis of large gene lists using DAVID bioinformatics resources. Nat Protoc 2009; 4: 44-57.

56. Huang da W, Sherman BT, Lempicki RA. Bioinformatics enrichment tools: paths toward the comprehensive functional analysis of large gene lists. Nucleic Acids Res 2009; 37: 1-13.

57. Chadwick BP, Willard HF. Histone H2A variants and the inactive $X$ chromosome: identification of a second macroH2A variant. Hum Mol Genet 2001; 10: 1101-1113.

\section{Supplementary Information accompanies this paper on Cell Death and Differentiation website (http://www.nature.com/cdd)}

